This item was submitted to Loughborough's Research Repository by the author.

Items in Figshare are protected by copyright, with all rights reserved, unless otherwise indicated.

\title{
Trial fitting of a removable partial denture framework made using computer- aided design and rapid prototyping techniques
}

PLEASE CITE THE PUBLISHED VERSION

PUBLISHER

Professional Engineering Publishing / @ IMechE

VERSION

VoR (Version of Record)

LICENCE

CC BY-NC-ND 4.0

\section{REPOSITORY RECORD}

Bibb, Richard J., Dominic Eggbeer, R.J. Williams, and A. Woodward. 2019. "Trial Fitting of a Removable Partial Denture Framework Made Using Computer-aided Design and Rapid Prototyping Techniques”. figshare. https://hdl.handle.net/2134/5710. 
This item was submitted to Loughborough's Institutional Repository (https://dspace.lboro.ac.uk/) by the author and is made available under the following Creative Commons Licence conditions.

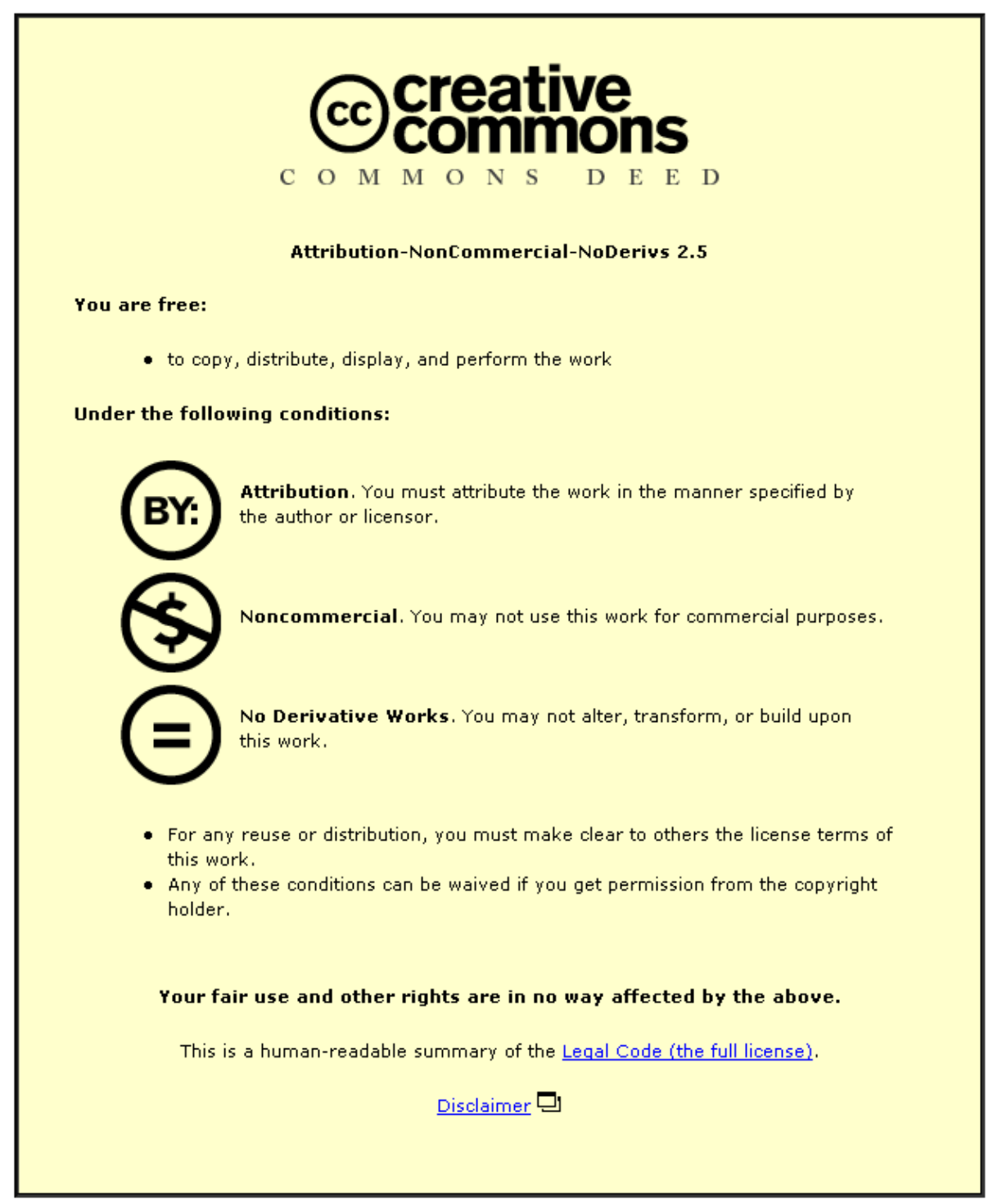

For the full text of this licence, please go to: http://creativecommons.org/licenses/by-nc-nd/2.5/ 


\title{
Trial fitting of a removable partial denture framework made using computer-aided design and rapid prototyping techniques
}

\author{
R J Bibb ${ }^{1 *}$, D Eggbeer ${ }^{1}$, R J Williams ${ }^{2}$, and A Woodward ${ }^{3}$ \\ ${ }^{1}$ National Centre for Product Design \& Development Research, University of Wales Institute Cardiff, Cardiff, South \\ Glamorgan, UK \\ ${ }^{2}$ Centre for Dental Technology, University of Wales Institute, Cardiff, UK \\ ${ }^{3}$ Welsh National School of Medicine, UK
}

The manuscript was received on 1 June 2005 and was accepted after revision for publication on 4 July 2006.

DOI: 10.1243/09544119JEIM62

\begin{abstract}
Previous studies of CAD/CAM-produced sacrificial patterns for removable partial denture frameworks have been documented but to date, no such restorations have been testfitted to a patient. This paper provides details of the first trial fitting to a patient of an RPD framework, the sacrificial pattern of which was produced by CAD/CAM and RP technologies. A cast of the patient was scanned and the normal procedures of dental surveying and pattern build were undertaken with reference to the scanned model using computer-aided design. A sacrificial pattern of the design was produced by rapid prototyping technology. After spruing the pattern, investment-casting and finishing techniques were carried out according to conventional principles. The framework was successfully trial-fitted to the patient and clinically judged to be acceptable for the next stage of denture fabrication, that of adding acrylic bases and artificial teeth.
\end{abstract}

Keywords: computer-aided design, rapid prototyping, removable partial denture

\section{INTRODUCTION}

Computer-aided design and manufacture (CAD/CAM) techniques have been adopted as a method of fabrication for fixed partial denture restorations $[\mathbf{1}, \mathbf{2}]$ and $\mathrm{CAD} / \mathrm{CAM}$ and rapid prototyping $(\mathrm{RP})$ have been extensively used in maxillofacial technology and surgery [3-5]. The application of the principles of CAD and RP to the fabrication of removable partial denture frameworks (RPDs) is in the early stage of development but already the potential advantages are clear and have been discussed [6-8]. Developments achieved so far include electronic surveying of a three-dimensionally scanned dental cast [7] and the production of successful castings from plastic patterns produced by RP technologies $[\mathbf{6}, \mathbf{8}]$. The potential

\footnotetext{
* Corresponding author: National Centre for Product Design \& Development Research, University of Wales Institute Cardiff, Western Avenue, Cardiff, South Glamorgan, CF5 2YB, UK. email: rbibb-pdr@uwic.ac.uk
}

future benefits include a rapid and semi-automated method of digital surveying, a 'drag and drop' system of virtual patterning using on-screen icons of RPD components, which could be dragged onto the computer model of a scanned cast of a patient.

However, although the castings fabricated so far by CAD/CAM-produced patterns are judged to have been acceptable for clinical presentation, to date, none has been trial-fitted to a patient. This case report follows on from previously published work by providing details of the first fitting to a patient of an RPD framework produced by CAD and RP technologies.

\section{METHODS}

\subsection{The case}

A female patient presented to the University Hospital of Wales Dental School with all lower anterior teeth present along with the lower left premolar (referred 
to as a Kennedy class 1 case). There was some retroclination, especially of the second incisors, the canines, and the premolar. The most viable form of treatment was considered to be the provision of a cobalt-chromium metal alloy framework RPD. A design based on the 'Rest, Proximal plate, I clasp' (RPI) [9] principle was formulated.

\subsection{Data capture and digital RPD design}

The master cast of the patient's mandibular dental structures was three-dimensionally scanned using a structured white light digitizer. The device used is an optical system that utilizes a projected fringepattern of light and digital camera technology to capture approximately 140000 points in three dimensions on the surface of the object (Comet 250, Steinbichler Optotechnik GmbH, Am Bauhof 4, D-83115 Neubeuern, Germany). The data points collected are referred to as a 'point cloud'. The fringe pattern can be seen in Fig. 1 .

Software (PolyWorks ${ }^{\circledR}$, InnovMetric Software Inc., 2014 Jean-Talon Blvd. North, Suite 310, SainteFoy, Quebec, G1N 4N6, Canada) was used to combine automatically multiple scans (overcoming the problems caused by line of sight) by aligning overlapping areas of scan data. A further software package (Spider, Alias-Wavefront Inc., 210 King Street East, Toronto, Ontario, M5A 1J7, Canada) was used to produce a triangular-faceted surface model from the point cloud data, shown in Fig. 2 .

The surface of the computer model created from the point cloud was produced using triangular polygons in the form of a stereolithography (STL)

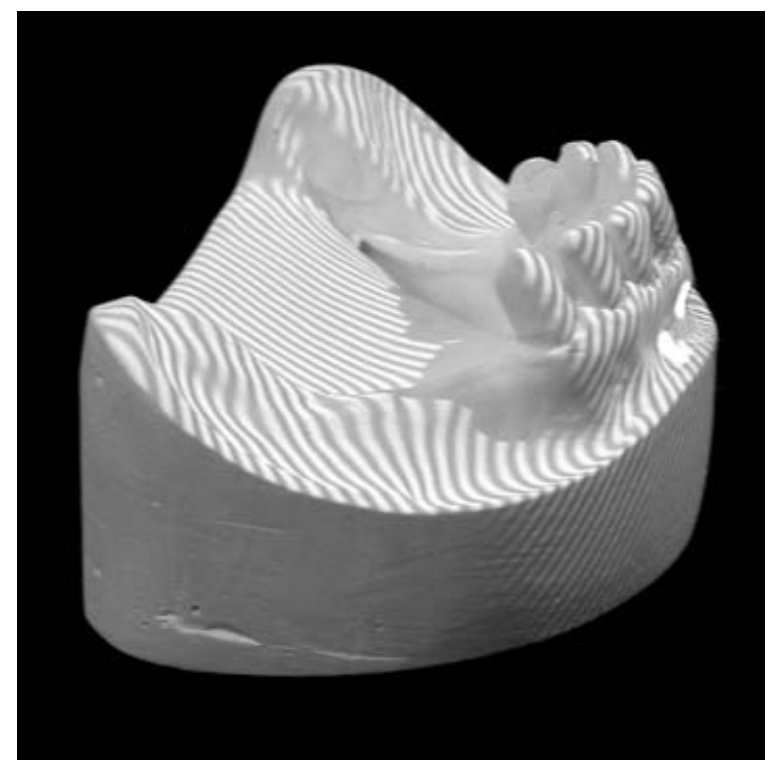

Fig. 1 Lateral view of master cast undergoing scanning

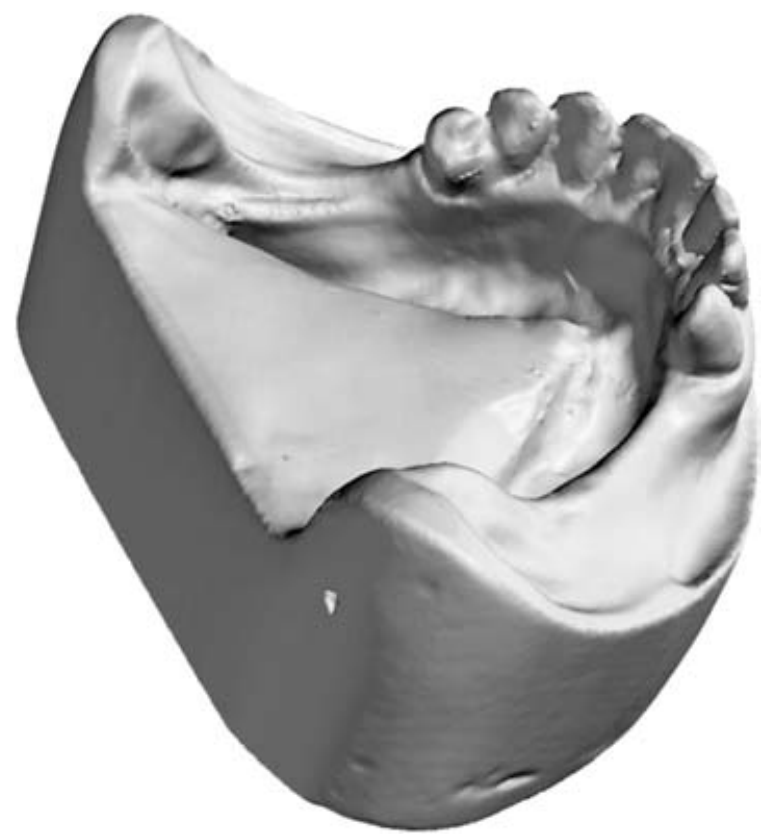

Fig. 2 The solid computer model of the patient's cast

file, which is a suitable format for importing into the virtual sculpting environment, FreeForm ${ }^{\circledR}$. This facility was used to survey electronically the scanned model according to the principles outlined by Williams et al. [7]. Although no undercuts were present in the areas of clasp engagement on the abutment teeth, FreeForm ${ }^{\circledR}$ is able to measure undercuts, as discussed by Williams et al. [7].

Once surveying was completed, the model was saved in a protected manner, so that it could not be altered inadvertently during the next stage of virtual patterning. A pattern was designed 'on screen' according to that discussed above on the digitally scanned model. The design followed the principles described more fully in previous work $[\mathbf{8}, 10]$. Again, the package FreeForm ${ }^{\circledR}$ provided excellent facilities for this process. Accurately defined, semicircular profiles such as the lingual bar were built up using construction curves; then a 'groove' tool was used to create a raised section. 'Smudge' and 'smooth' tools were used to merge the components together. The process is illustrated in Figs 3(a)-(c).

\subsection{Rapid prototyping and investment casting}

Previous work had indicated that stereolithography was capable of producing suitable sacrificial patterns of RPDs $[8,10]$. Compared to other RP techniques, stereolithography patterns were found to possess a good balance of properties being rigid enough to hold their shape, thus maintaining accuracy while being tough enough to allow handling and investment 


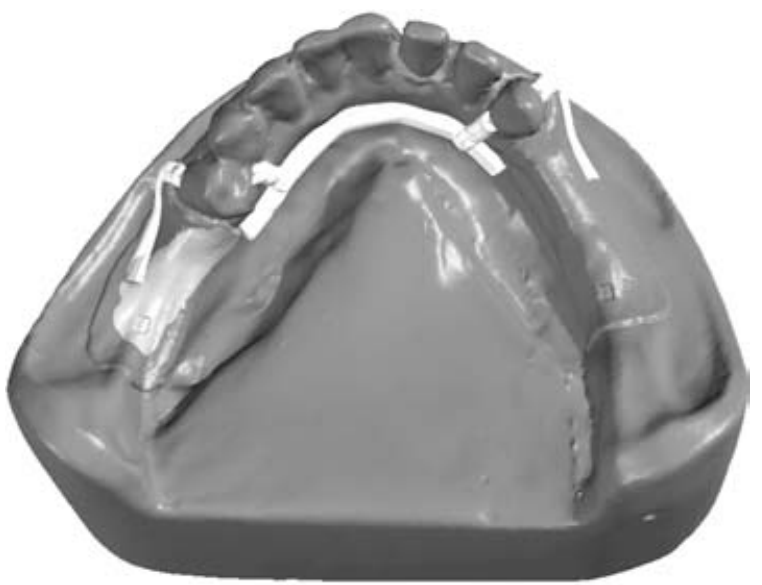

(a)

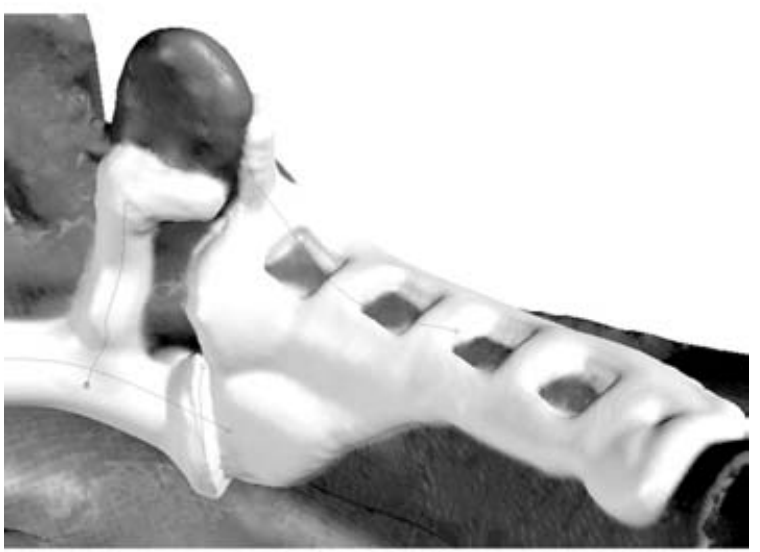

(b)

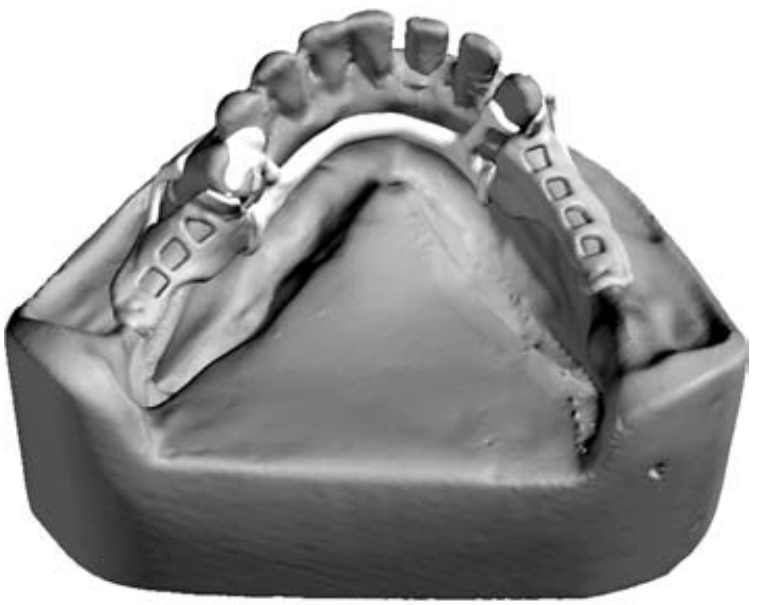

(c)

Fig. 3 (a) Illustration of the major and minor connectors, gingivally approaching clasps and area of retention for acrylic defined; (b) right side of framework at a later stage of development with components joined; (c) the final digital pattern

casting without inadvertent damage. Therefore, in this case, once the digital design had been finalized, a stereolithography RP machine (SLA 250/40; 3D Systems Inc, 26081 Avenue Hall, Valencia, California
91355, USA) was used to build a physical pattern in epoxy-based resin (WaterClear 10110; DSM Somos, New Castle, Delaware, USA).

The 'fine-point' supporting structures of the sacrificial pattern were thin and easily removed with a scalpel. The pattern then had wax sprues attached and was investment cast according to the procedures typically used in dental technology with the exception of the use of a refractory model. The pattern was cast directly in cobalt-chromium alloy and finished by grit-blasting and polishing in the normal manner. The framework was then test-fitted to the master cast, shown in Fig. 4. Test-fitting indicated a good fit and the framework was forwarded to the dental clinic.

This project was undertaken as an elective and was submitted for approval to the internal and external supervisors at the Welsh National School of Medicine. In this case informed consent was required and subsequently obtained from the patient to undertake a single trial fitting of the experimental framework. The patient was not inconvenienced further and was provided with a partial denture produced using standard techniques.

\section{RESULTS}

The framework was prepared for test-fitting to the patient in the usual manner. The framework was testfitted on the patient by a dentist (clinical supervisor). When fitted to the patient, on initial insertion, there were some discrepancies but with some adjustment with reference to the patient in the dental clinic, the framework fitted satisfactorily, as shown in Fig. 5. It is not unusual for a cast RPD framework to require minor adjustment in order to fit the patient perfectly

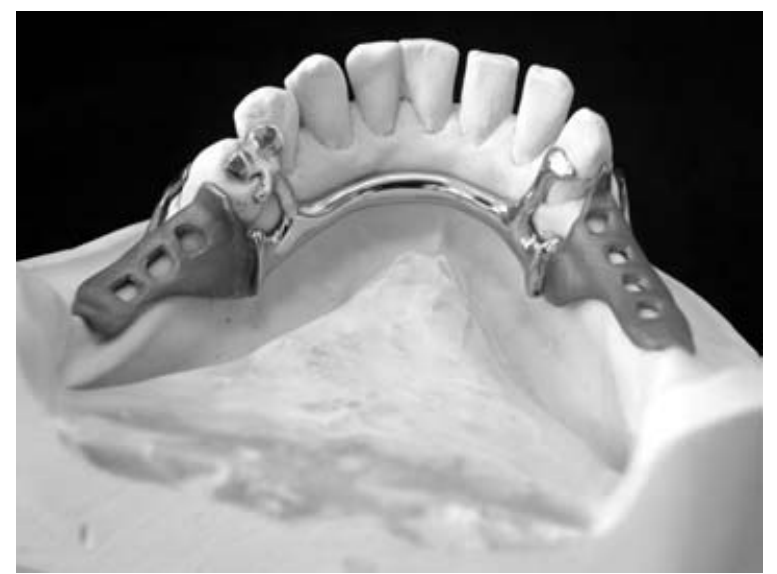

Fig. 4 Metal alloy framework ready for clinical presentation 


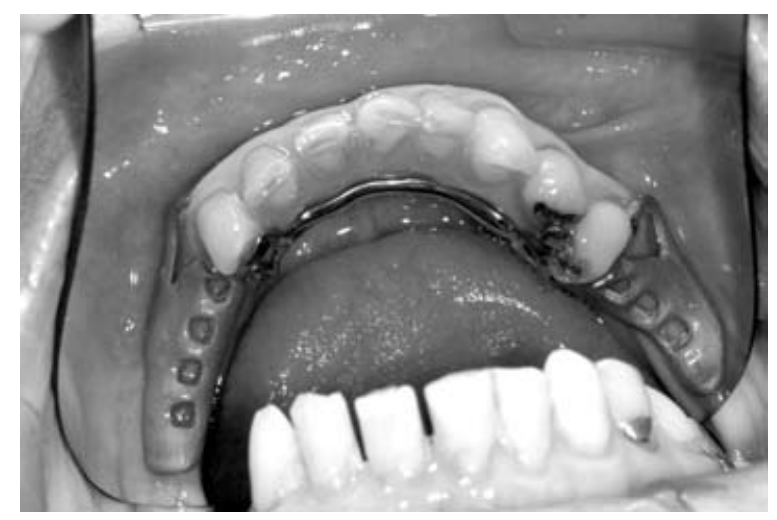

Fig. 5 The framework in situ

as there may be slight differences between the patient anatomy and the cast. The clinical supervisor also confirmed that the alloy framework was satisfactory and that it could proceed to the next stage of construction, that of adding acrylic bases and artificial teeth.

\section{DISCUSSION}

The concept of introducing CAD/CAM into the fabrication of RPD frameworks is taken a step further than previous work $[\mathbf{8}, \mathbf{1 0}]$. The successful trial-fitting of the cast cobalt-chromium framework to an actual patient in the clinic has indicated that the accuracy, tolerances, and overall 'fitness for purpose' suggested in previous research $[\mathbf{1 0}]$ can be achieved in an actual clinical case. Although considerable time was involved in producing a framework by this method, it is foreseeable that with more research, the time could be reduced greatly, making the computeraided method competitive with existing conventional techniques.

The fact that the framework was judged to be acceptable by an independent dentist (clinical supervisor) indicates that the application of CAD/RP techniques to this field stands comparison with existing casting techniques and suggests that there is potential for further investigation. Although the resulting framework required some minor adjustment to achieve a perfect fit, the nature and extent of this adjustment was comparable to that normally undertaken with cast frameworks produced by existing techniques. This suggests that the stereolithography casting pattern was of comparable accuracy to the wax patterns produced by existing techniques.

As this trial case has proved, promising further cases will be undertaken to verify that the technique is repeatable and consistent and test-fitting will also be assessed by physical measurement.
Future research will explore multiple clinical cases of finished prostheses, as well as the application of direct RP technologies such as selective laser melting that could be used to build frameworks in appropriate metal alloys, thus eliminating the casting stage altogether.

\section{CONCLUSIONS}

This paper demonstrates that a clinically satisfactory RPD framework can be designed and produced by CAD and an RP-built sacrificial pattern. A framework fabricated by the methods described was clinically verified and found to be acceptable and suitable to proceed to the next stage of RPD construction and clinical use.

\section{ACKNOWLEDGEMENT}

The authors are grateful to Mrs Rowena Bevan for her invaluable support.

\section{REFERENCES}

1 van der Zel, J., Vlaar, S., de Ruiter, W., and Davidson, C. The CICERO system for CAD/CAM fabrication of full ceramic crowns. J. Prosthetic Dent., 2001, 85, 261-7.

2 Mormann, w. H. and Bindl, A. The CEREC 3-a quantum leap for computer-aided restorations: initial clinical results. Quintessence Int., 2000, 31, 699-712.

3 Hughes, C. W., Page, K., Bibb, R., Taylor, J., and Revington, P. The custom-made titanium orbital floor prosthesis in reconstruction for orbital floor fractures. Br. J. Oral and Maxillofacial Surg., 2003, 41, 50-53.

4 Bibb, R. and Brown, R. The application of computer aided product development techniques in medical modeling. Biomed. Sci. Instrumn, 2000, 36, 319-324.

5 Bibb R., Bocca, A., and Evans, P. An appropriate approach to computer aided design and manufacture of cranioplasty plates. J. Maxillofacial Prosthetics Technol., 2002, 5, 28-31.

6 Williams, R., Bibb, R., and Rafik, T. A technique for fabricating patterns for removable partial denture frameworks using digitized casts and electronic surveying. J. Prosthetic Dent., 2004, 91, 85-88.

7 Williams, R., Eggbeer, D., and Bibb, R. CAD/CAM in the fabrication of removable partial denture frameworks: a virtual method of surveying 3-dimensionally scanned dental casts. Quintessence J. Dent. Technol., 2004, 2, 242-267.

8 Eggbeer, D., Williams, R., and Bibb, R. A digital method of design and manufacture of sacrificial 
patterns for removable partial denture metal frameworks. Quintessence J. Dent. Technol., 2004, 2, 490-499.

9 Kratchovil, F. J. Influence of occlusal rest position and clasp design on movement of abutment teeth. J. Prosthetic Dent., 1963, 13, 114-124.
10 Eggbeer, D., Bibb, R., and Williams, R. The computer-aided design and rapid prototyping fabrication of removable partial denture frameworks. Proc. IMechE, Part H: J. Engineering in Medicine, 2005, 219, 195-202. 